\title{
Study on Low Carbon Transition for Hazardous Chemical Packaging Based on Life Cycle Assessment and Grey Model
}

\section{Zhijie Feng ${ }^{1,2}$, Lin Zhao, ${ }^{1, *}$, Shuai Wang ${ }^{1}$ and Qian Hou ${ }^{2}$}

1 School of Environmental Science and Engineering, Tianjin University, Tianjin 300072, China; jasper.f@163.com

2 Tianjin Entry-Exit Inspection and Quarantine Bureau, Tianjin 300201, China

* Correspondence: zhaolin@tju.edu.cn

\begin{abstract}
The purpose of this paper was to analyze the development trend of hazardous chemical packaging towards low carbon economy from both qualitative and quantitative perspectives. Four types of relatively small volume packaging with volume/weight less than $450 \mathrm{~L} / 400 \mathrm{~kg}$, respectively, and three intermediate bulk containers (IBCs), which are widely used for hazardous chemicals were studied to calculate the carbon footprint (CF) from cradle to grave using life cycle assessment (LCA) method and to predict the future carbon emission of hazardous chemical packaging in the next five years (2016-2020), based on the export data of Tianjin Port in China. Grey model (GM) was adopted in the prediction. The results showed that majority of IBCs have lower carbon footprint than other types when the packaging contained same amount of same hazardous chemical. With the development of international trading, the demand of hazardous chemicals will increase as well. As the result, carbon emission generated by hazardous chemical packaging will increase accordingly. However, based on GM simulation result, increasing the amount of IBC use will effectively reduce the relative amount of carbon emission.
\end{abstract}

Keywords: packaging; hazardous chemicals; life cycle assessment (LCA); grey model (GM); IBCs; carbon footprint (CF)

\section{Introduction}

Since 17th century, industrial revolution has brought huge development to human civilization. Packaging industry achieved great development by leaps and bounds [1, 2]. However, modern packaging industry exploited resources in an inappropriate way and also adopted a high energy consumption, pollution and emission production mode, which increased scarcity of global resources and worsened the global environment. Under the background of low carbon economy, a broader awareness of sustainable development of packaging has been aroused [3]. Low carbon economy is a human rational choice in accordance with the fundamental interests of human development [4].

The earliest research of LCA started from packaging field, which can date back to 1969 when the Coca-cola Company described the different resources consumption and environmental release regarding to different containers of drinking. Therefore, in recent 50 years, the research achievements of fruitful package field mainly focus on the food package field, including packaging for cheese products [5], alcohol products [6] as well as 
fruit and vegetable packaging [7], etc. Through comparative study, packaging products more friendly to the environment will be innovated. Feng, etc. [8] conducted research to compare the life cycle for fiberboard IBCs and fiberboard boxes, and showed that fiberboard IBCs has obvious advantages over the fiberboard boxes in the comparative analysis of life cycle, including 11 categories of impact on the environment. Among them, the biggest gap is ozone depletion damage, only $60 \%$ of the fiberboard boxes, while the smallest is the acidification/eutrophication, $90 \%$ of the fiberboard boxes. On terms of life-cycle stages, IBC has greatest advantages in the raw material production phase, while minimum in use phase. Researchers preferred to assess carbon footprint by using LCA in recent years. The research of packaging carbon footprint focused on food packaging [9-11] and the related one in the field of consumption concept and consumption behavior [12, 13].

According to the 'UN Transport of dangerous goods model regulations' [14], there are almost $2830 \mathrm{UN}$ numbers to represent the different of dangerous goods, of which about $90 \%$ are hazardous chemicals. Hazardous chemicals have had a profound impact on health, environment, economy, etc. [15]. Meanwhile, the hazardous chemical accidents, such as the huge chemical explosion at the Chinese port of Tianjin on Aug.12th 2015, called for the control on different life cycle stages of dangerous chemicals [16]. As a special part of commodity packaging, hazardous chemical packaging has gained much attention, since its characteristics are inflammable, explosive and corrosive which could bring adverse impact on human being and environment. Research on hazardous chemical packaging was mainly focused on the influential ensure product safety [17-19], such as safety test technology, product design, etc. However, there have been fewer studies on life cycle and carbon footprint. One study on life cycle assessment for fiberboard box and fiberboard IBCs in the loading amount of hazardous chemicals showed that fiberboard IBCs was more environmental friendly.

Tianjin port as one of the largest ports in north of China [20], could be a very good representative for the status of the import and export of hazardous chemicals in packaging batch, type, quantity, etc. in China. Using the export data from Tianjin Port could better reveal the influence from the development of type, material, quantity of hazardous chemical packaging on the low carbon economy. This paper used Tianjin port exported hazardous chemical packaging from 2012 to 2015 as the research object and chose seven common types of packaging ( 4 kinds of small volume packaging, 3 kinds of IBCs) to conduct product life cycle analysis and quantitative calculation of their carbon footprint.

With the existing data, grey model (GM) was used to calculate carbon footprint changing trend of the studied packaging products in Tianjin port during five years from 2016 to 2020. By analyzing the change in the relationship between hazardous chemical packaging type and its carbon footprint, a sustainable development model with lower carbon footprint - more friendly to environment could be established for hazardous chemical packaging industry. Furthermore, this would help realize the economic and social sustainable development. Therefore, research on industrial structure change on hazardous chemical packaging will be significant for the whole packaging industry. 


\section{Methodologies}

\subsection{Life Cycle Assessment}

Based on the conception of life cycle, life cycle assessment (LCA) is regarded as a useful tool to estimate and assess the environmental impacts of a product or process by identifying and quantifying energy and materials used and wastes released to the environment, from 'cradle to grave' [21]. In addition, a cradle to cradle perspective [22] and a gate to gate assessment have also been introduced in recent years, when analyzing specific production processes or systems. Therefore, conducting a whole life cycle analysis of each packaging will give a comprehensive comparison in the field of hazardous chemical packaging.

The interest in LCA has grown rapidly in last decades because of the increasing awareness of environment protection and sustainable development. Now, it has been used in a wide range of research areas to evaluate environmental impacts. The main phrase of LCA can be divided into 4 steps according the international standards [23]:1) Goal and Scope definition; 2) Inventory analysis; 3) Impact assessment; 4) Interpretation. Figure 1 illustrates the conception framework of common LCA analysis. And it includes different models to evaluate different items, for example, IPCC used in this study is for carbon emissions and Eco-indicator 99 is for general environmental impacts.

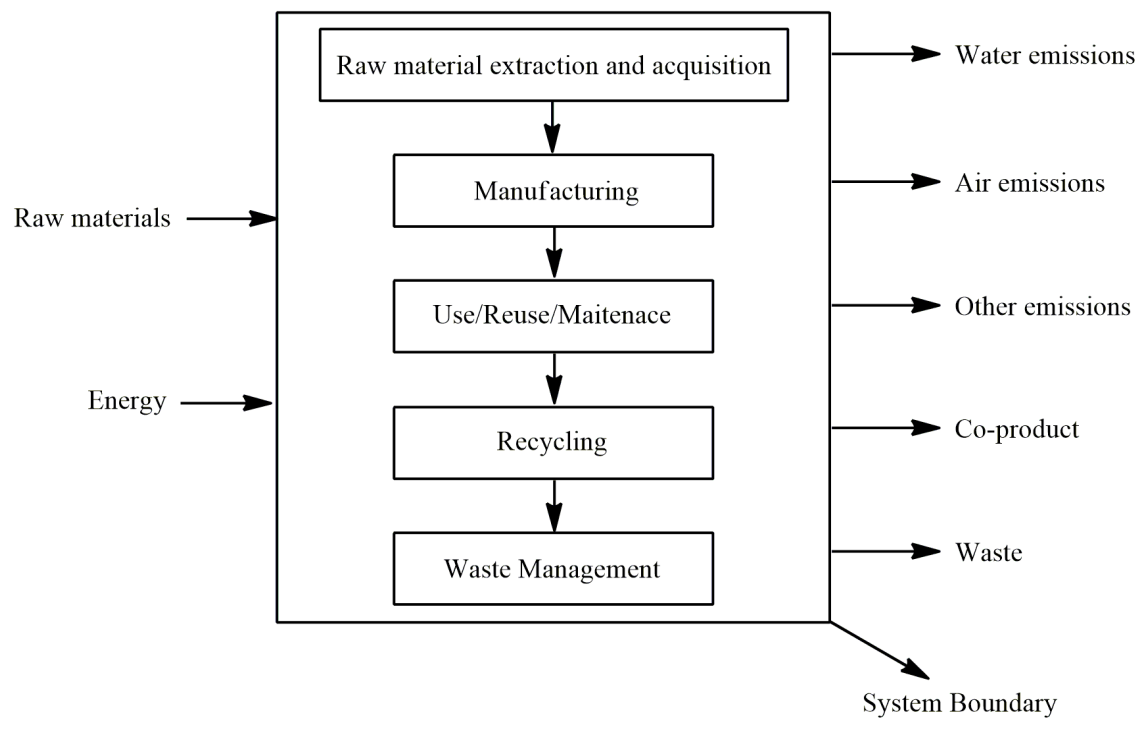

Figure 1. Scope of Life Cycle Assessment [23].

\subsection{Carbon Footprint}

Originated from LCA, carbon footprint is a worldwide standardized indicator of greenhouse gas (GHG) emissions through the whole life cycle of a particular product, process or activity [24]. Carbon dioxide is regarded as the largest contributor to climate change [25]. Therefore, $\mathrm{CF}$ is expressed in carbon dioxide equivalent $\left(\mathrm{CO}_{2}\right.$ eq.) [26], measuring the total greenhouse gas emissions directly caused by individual, activity, organization or product [27]. So it is necessary to analyze the $C F$, since it is one of the highlights of all concerns related to environmental issues, of representative dangerous chemicals' packages. It is useful to quantify the impact of human activities on the 
environment and global climate by assessing the quantity of emission from different carbon emitting sectors [28]. LCA model is used in this study to calculate the CF for covering the entire life cycle of the analyzed product.

\subsection{Structure and Steps}

In this study, LCA was used to analyze and compare the CF of seven hazardous chemical packaging (fiberboard boxes, steel drums, plastic drums, plastic woven bags, flexible IBCs, fiberboard IBCs and steel-plastic composite IBCs), aiming to give replacement trend in this field in order to achieve low-carbon economy. According to the process of LCA, CF was calculated in four steps in this paper, which was illustrated in Figure 2. And IPCC 2013 model was chosen to assess the carbon footprint of each packaging through its whole life cycle. IPCC 2013 is an assessment model established by Intergovernmental Panel on Climate Change [25], with the purpose of giving a comprehensive evaluation of all types of greenhouse gases which have global warming potential. Its results can be present by three indicators: GWP 20a, GWP 100a and GWP $500 \mathrm{a}$, which presenting greenhouse effect of short-term, medium-term and long-term respectively. Since the work was to analyze and predict the $\mathrm{CF}$ of each packaging in a short time period, GWP 20a was used in this study.

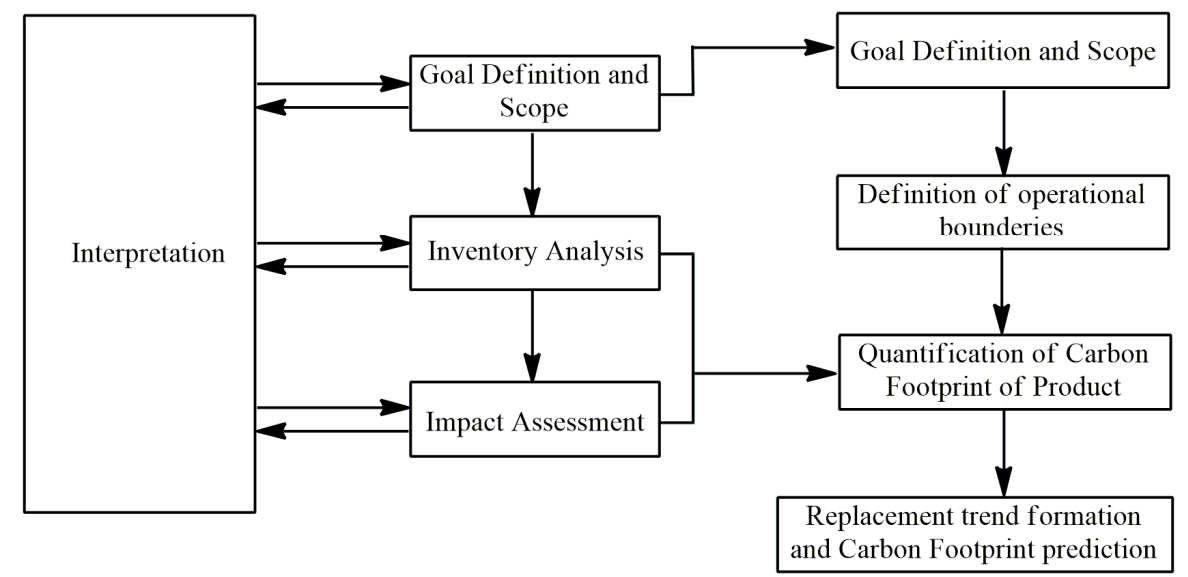

Figure 2. Four Steps to Assess Carbon Footprint.

\subsection{Grey Model}

Grey model is based on grey system theory, which aims to predict the behavior of systems with limited data [29]. It was first introduced by Deng in 1982 [30]. Different from common statistical models, grey model is an alternative forecasting tool for those systems of complex, uncertain and chaotic structure [31]. A limited amount of data is required to predict the behaviors of unknown systems [32]. Using grey model to make a grey prediction basically has three operations: accumulated generating operation (AGO), inverse accumulated generating operation (IAGO) and grey modeling. Although, there are many different grey prediction models, the most commonly used one is GM $(1,1)$ [33]. And steps of setting up GM $(1,1)$, which was used to forecast the carbon emission trend of hazardous chemical packaging for the next 5 years in this study with the help of 
Matlab, are as following:

Set the non-negative time-sequence data:

Calculating the AGO:

where, $\mathrm{k}=1,2, \ldots, \mathrm{n}$;

$, \mathrm{k}=1,2, \ldots, \mathrm{n}$;

Then, the GM $(1,1)$ is as follows:

where, "a" is called "develop parameter" and " $b$ " is called "grey input".

Estimating the with the least square method:

where,

and

Then response equation can be:

The response equation of GM $(1,1)$ can be:

$$
, \mathrm{k}=1,2, \ldots, \mathrm{n} \text {. }
$$

While, $\mathrm{k}=1,2, \ldots, \mathrm{n}$.

And the predicted value can be:

$$
, \mathrm{k}=1,2, \ldots, \mathrm{n} \text {. }
$$

\section{Data Source and Studied Packaging}

\subsection{Data Source}

This work was based on the export data of Tianjin port from the statistic data of Tianjin Entry-Exit Inspection and Quarantine Bureau and selected export quantity in practical use of fiberboard boxes, steel drums, plastic drums, plastic woven bags, flexible IBCs, fiberboard IBCs and steel-plastic composite IBCs. These seven type packaging were chosen as the research object based on the volume and category of export dangerous goods of Tianjin in 2014. They accounted for about $88.6 \%$ of the whole export dangerous goods packaging, taking an absolutely big share in this field (see Table 1).

Table 1. Volume \& category of export dangerous goods of Tianjin in 2014

\begin{tabular}{llrr}
\hline \multicolumn{1}{c}{ Category of packaging } & \multicolumn{1}{c}{ Packaging } & Batch & Percentage (\%) \\
\hline \multirow{4}{*}{ Small volume packaging with } & Fiberboard boxes & 1097 & 17.12 \\
& Fiberboard drums & 63 & 0.98 \\
volume/weight less than & Steel drums & 1703 & 26.58 \\
$450 \mathrm{~L} / 400 \mathrm{~kg}$, respectively & Plastic drums & 29 & 0.45 \\
& Plastic jerricans & 1257 & 19.6 \\
& Plastic woven bags & 417 & 6.51 \\
& Paper bags & 932 & 14.54 \\
& & 108 & 1.69 \\
\hline
\end{tabular}




\begin{tabular}{llrl}
\hline & Steel-plastic composite drums & 23 & 0.36 \\
& Wood boxes & 3 & 0.05 \\
& Plywood boxes & 26 & 0.41 \\
\hline \multirow{3}{*}{$\begin{array}{l}\text { Intermediate bulk containers } \\
\text { (IBCs) }\end{array}$} & Fiberboard IBCs & 14 & 0.22 \\
& Flexible IBCs & 415 & 6.48 \\
& Steel-plastic composite IBCs & 232 & 3.62 \\
& Wood IBCs & 2 & 0.03 \\
\hline \multirow{2}{*}{ Small gas pressure vessels } & Small gas pressure vessels & 87 & 1.36 \\
\hline & Total & $\mathbf{6 4 0 8}$ & $\mathbf{1 0 0}$ \\
\hline
\end{tabular}

\subsection{Studied Packaging}

We selected the above seven type packaging products of the specifications of the representative model as the research object, as demonstrated in Table 2. Product life cycle data were collected from several production enterprises in Tianjin region, respectively. When choosing the enterprises, on one hand, packaging production enterprises with larger export quota were chosen as the research object to ensure the representation of the data. On the other hand, data of packaging made of same material were collected from the same enterprise to ensure the comparability of different types of packaging.

Table 2. Life Cycle Data Acquisition Packaging Specifications and Companies List.

\begin{tabular}{|c|c|c|c|}
\hline $\begin{array}{r}\text { Category of } \\
\text { packaging }\end{array}$ & Packaging & Specification and dimension & Related enterprise \\
\hline \multirow{4}{*}{$\begin{array}{l}\text { Small volume } \\
\text { packaging with } \\
\text { volume/weight } \\
\text { less than } \\
450 \mathrm{~L} / 400 \mathrm{~kg} \text {, } \\
\text { respectively }\end{array}$} & Fiberboard boxes & $\begin{array}{l}25 \mathrm{~kg} \text { double corrugated carton } \\
\text { box }\end{array}$ & $\begin{array}{l}\text { Seven Industrial } \\
\text { (Tianjin) co., Ltd. }\end{array}$ \\
\hline & Steel drums & $\begin{array}{l}216.51[34] \\
(\phi 590 \mathrm{~mm}, \mathrm{H} \mathrm{900mm}) \text { weight } \\
11 \mathrm{~kg}\end{array}$ & $\begin{array}{l}\text { Tianjin DaTian } \\
\text { Packaging Container } \\
\text { Co., Ltd }\end{array}$ \\
\hline & Plastic drums & $\begin{array}{l}2201[35] （ \phi 581 \mathrm{~mm}, H 935 \mathrm{~mm}) \\
\text { weight } 8.5 \mathrm{~kg}\end{array}$ & $\begin{array}{l}\text { Schuetz Container } \\
\text { Systems (Tianjin) Co., } \\
\text { Ltd. }\end{array}$ \\
\hline & $\begin{array}{l}\text { Plastic woven } \\
\text { bags }\end{array}$ & $\begin{array}{l}25 \mathrm{~kg} \text { three layers of plastic woven } \\
\text { bags }\end{array}$ & $\begin{array}{l}\text { Tianjin XuHui } \\
\text { HengYuan Plastic } \\
\text { Packaging Corp. }\end{array}$ \\
\hline \multirow{3}{*}{$\begin{array}{l}\text { Intermediate bulk } \\
\text { containers } \\
\text { (IBCs) }\end{array}$} & Fiberboard IBCs & $\begin{array}{l}\text { 1t,seven layers of corrugated } \\
\text { cardboard } \\
\quad(1100 \mathrm{~mm} \times 1100 \mathrm{~mm} \times 1100 \mathrm{~mm})\end{array}$ & $\begin{array}{l}\text { Seven Industrial } \\
\text { (Tianjin) co., Ltd. }\end{array}$ \\
\hline & Flexible IBCs & 1t three layer, compilation plastic & $\begin{array}{l}\text { Tianjin XuHui } \\
\text { HengYuan Plastic } \\
\text { Packaging Corp. }\end{array}$ \\
\hline & $\begin{array}{l}\text { Steel-plastic } \\
\text { composite IBCs }\end{array}$ & 10501 Steel-plastic composite IBCs & $\begin{array}{l}\text { Schuetz Container } \\
\text { Systems (Tianjin) Co., } \\
\text { Ltd. }\end{array}$ \\
\hline
\end{tabular}

\section{Analysis of hazardous chemical packaging}

\subsection{Goal and Scope}

The first step of LCA is to define goal and scope, i.e., define the objectives and setting the system boundaries [36]. The objective of this study was to assess and compare the 
carbon footprint of seven hazardous chemical packaging and to forecast their carbon emission trends in Tianjin Port in the next five years, which provides assistance to package industry transition towards low carbon economy.

The selected types of packaging are fiberboard boxes, fiberboard IBCs, plastic woven bags, flexible IBCs, steel drums, plastic drums and steel-plastic composite IBCs. The whole life cycle of each packaging type from cradle to grave was analyzed in this study. Since Functional unit is the basis for comparison among the packaging, and the chosen packaging could work for both liquid and solid, unit loading weight capacity of $1 \mathrm{~kg}$ was chosen as the modeling basis in the case.

\subsection{Inventory Analysis}

In this study, the whole life cycle of packages was involved, from cradle to grave. Most inputs and outputs for each process were listed in Table 3, except for unavailable and uncertain data which almost do not affect the whole analysis. The modes of recycled packages vary according to their characteristics of material. Because of different materials of the packaging, the analyzing boundaries covered waste management phase according to the average level in China, and disposal was considered as the end of a single-used life cycle on site without transportation. Moreover, we chose the concrete with nearest density in the database of SimaPro. To conduct the carbon footprint analysis across with the life cycle, the assessment was made based on IPCC2013 GWP 20a. During the use of the packaging, there were minimal input and output related to the CF. Therefore, the inventory did not include the stage of use.

Table 3. Life Cycle Inventory of Packages.

\begin{tabular}{|c|c|c|c|c|c|c|c|c|}
\hline \multicolumn{2}{|c|}{ Packaging } & $\begin{array}{l}\text { Fiberboard } \\
\text { boxes }\end{array}$ & $\begin{array}{l}\text { Fiberboard } \\
\text { IBCs }\end{array}$ & $\begin{array}{c}\text { Plastic } \\
\text { woven } \\
\text { bags }\end{array}$ & $\begin{array}{l}\text { Flexible } \\
\text { IBCs }\end{array}$ & $\begin{array}{l}\text { Steel } \\
\text { drums }\end{array}$ & $\begin{array}{l}\text { Plastic } \\
\text { drums }\end{array}$ & $\begin{array}{c}\text { Steel-plastic } \\
\text { composite } \\
\text { IBCs } \\
\end{array}$ \\
\hline \multicolumn{2}{|c|}{ Capacity } & $25 \mathrm{~kg}$ & $1000 \mathrm{~kg}$ & $25 \mathrm{~kg}$ & $1000 \mathrm{~kg}$ & $208 \mathrm{~kg}$ & $210 \mathrm{~kg}$ & $1050 \mathrm{~kg}$ \\
\hline \multirow{10}{*}{ Production } & Material & $\begin{array}{l}\text { Fiberboard } \\
(\mathrm{g})\end{array}$ & $\begin{array}{c}\text { Fiberboard } \\
(\mathrm{g})\end{array}$ & $\mathrm{PP}(\mathrm{g})$ & $\mathrm{PP}(\mathrm{g})$ & $\begin{array}{c}\text { Cold steel } \\
(\mathrm{g})\end{array}$ & HDPE (g) & HDPE (g) \\
\hline & Amount & 600.75 & 14000 & 79 & 2140 & 20180 & 9500 & 16070 \\
\hline & Material & $\begin{array}{c}\text { Flat filament } \\
(\mathrm{g})\end{array}$ & $\begin{array}{c}\text { Flat } \\
\text { filament } \\
\text { (g) }\end{array}$ & -- & -- & $\begin{array}{l}\text { Coatings } \\
\text { (g) }\end{array}$ & $\mathrm{PP}(\mathrm{g})$ & $\begin{array}{l}\text { Steel tube } \\
\text { (g) }\end{array}$ \\
\hline & Amount & 2.3229 & 40.6 & -- & -- & 250 & 33 & 38000 \\
\hline & Material & Print ink (g) & $\begin{array}{l}\text { Print ink } \\
(\mathrm{g})\end{array}$ & -- & -- & $\begin{array}{c}\text { Adhesive } \\
\text { (g) }\end{array}$ & -- & -- \\
\hline & Amount & 2.0025 & 35 & -- & -- & 20 & -- & -- \\
\hline & Material & PE (g) & $\mathrm{PE}(\mathrm{g})$ & -- & -- & $\begin{array}{l}\text { Natural } \\
\text { gas }\left(\mathrm{m}^{3}\right)\end{array}$ & -- & -- \\
\hline & Amount & 0.75 & 500 & -- & -- & 0.3 & -- & -- \\
\hline & Energy & $\begin{array}{l}\text { Electricity } \\
(\mathrm{kWh})\end{array}$ & $\begin{array}{c}\text { Electricity } \\
(\mathrm{kWh})\end{array}$ & $\begin{array}{c}\text { Electricity } \\
(\mathrm{kWh})\end{array}$ & $\begin{array}{c}\text { Electricity } \\
(\mathrm{kWh})\end{array}$ & $\begin{array}{c}\text { Electricity } \\
(\mathrm{kWh})\end{array}$ & $\begin{array}{c}\text { Electricity } \\
(\mathrm{kWh})\end{array}$ & $\begin{array}{c}\text { Electricity } \\
(\mathrm{kWh})\end{array}$ \\
\hline & Amount & 0.03602 & 0.96 & 0.02 & 0.107 & 1.9 & 13.86 & 8.5 \\
\hline \multirow{3}{*}{ Transportation } & Vehicle & Trucks (8t) & Trucks (8t) & $\begin{array}{l}\text { Trucks } \\
(10.5 t)\end{array}$ & $\begin{array}{l}\text { Trucks } \\
\text { (10.5t) }\end{array}$ & $\begin{array}{c}\text { Trucks } \\
(35 \mathrm{t})\end{array}$ & $\begin{array}{c}\text { Trucks } \\
(35 t)\end{array}$ & Trucks (35t) \\
\hline & Loading & 4000 & 250 & 130000 & 5500 & 500 & 580 & 117 \\
\hline & Distance & $60 \mathrm{~km}$ & $60 \mathrm{~km}$ & $115 \mathrm{~km}$ & $115 \mathrm{~km}$ & $100 \mathrm{~km}$ & $150 \mathrm{~km}$ & $150 \mathrm{~km}$ \\
\hline \multirow{3}{*}{ Disposal } & Recycle & $30 \%$ & $30 \%$ & $15 \%$ & $15 \%$ & $2.50 \%$ & $15 \%$ & $50 \%$ \\
\hline & Landfill & $40 \%$ & $40 \%$ & $40 \%$ & $40 \%$ & $2.50 \%$ & -- & -- \\
\hline & Incineration & $30 \%$ & $30 \%$ & $45 \%$ & $45 \%$ & $95 \%$ & $85 \%$ & $50 \%$ \\
\hline
\end{tabular}

4.3. Quantification of Carbon Footprint of Product

Simapro was used to evaluate the carbon footprint of each analyzed package for a 
single-use life cycle. The result is illustrated in Figure 3. It is clear that normal IBCs have lower carbon footprint than other packages with similar material. For example, flexible IBCs exhaust GHG $6.07^{*} 10^{-3} \mathrm{~kg} \mathrm{CO} 2$ eq. when loading $1 \mathrm{~kg}$ solid, while plastic woven bags exhaust $9.8^{*} 10^{-3} \mathrm{CO}_{2}$ eq. It should be mentioned that steel drums have lower carbon footprint than steel-plastic composite IBCs, and the reason may be attributed to its high recycle level. However, according to practical situation, drum cleaning is a difficult task. Drums will hold residual liquid, resulting in adverse tore cycle again. Hence, steel-plastic composite IBCs will be a better choice when meeting the demand for re-use, although it has a little higher carbon footprint. Moreover, the steel-plastic composite IBCs are the most reused ones in fact, which can be reused 3 times every 3 years. It can be imagining that if reuse phase is added into consideration, the carbon footprint of steel-plastic composite IBCs will get lower, since recycling of steel is one of responsible factors for environmental advantage.

The key factor to determine the carbon footprint of a packaging is the type and amount of the material that is used to make the packaging. Compared with rigid plastic packaging, flexible plastic packaging uses relatively less material with higher recycle rate, so generally it is the best choice for hazardous chemicals. When containing same amount of chemicals, the flexible IBCs are more environmental friendly due to its less consumption of raw material.

Packaging recycling is also an important factor in determining the carbon footprint. Carbon emission in the production of plastic material is lower than production of steel, but the steel scrap can be used directly for smelting, and its recycle rate is higher. On the other hand, the plastic packaging, especially rigid plastic packaging, recycle rate is low, so the plastic drum shows the highest carbon footprint (Figure 3).

Another factor to determine the carbon footprint is the number of use. Cleaning and maintenance of packaging consume much less energy than producing a new packaging so that for a package used for $\mathrm{N}$ times, its carbon footprint becomes $1 / \mathrm{N}$. This is equivalent to reduce the material consumption for one packaging to $\mathrm{N}$ times less when the package can be used for $\mathrm{N}$ times.

Also, it can be seen from Figure 3, the packaging for solid product always achieves a better environmental performance, i.e., producing fewer GHG emissions than the one applicable for liquid. This may be caused by the fact that packaging for liquid need higher and more special performance and requirements so that its need more material consumption and environmental impacts can be much more. 


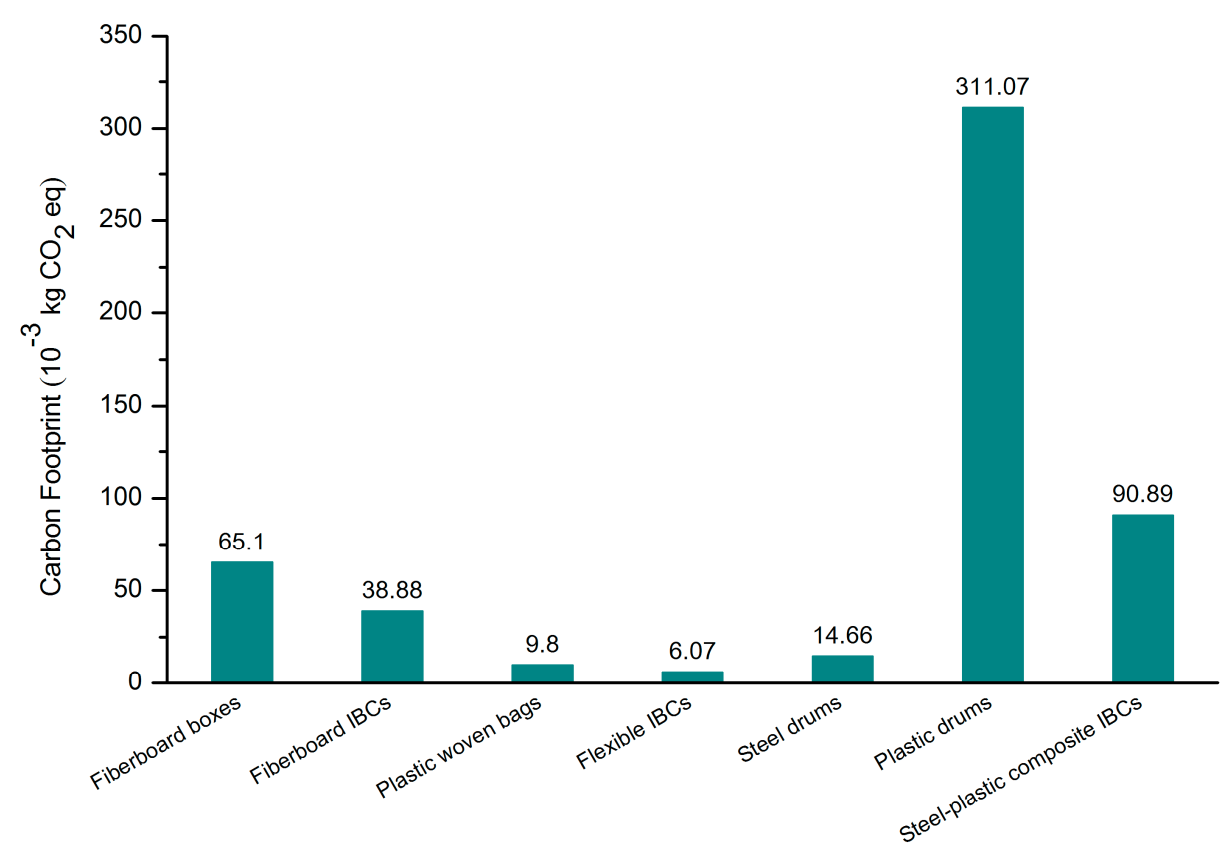

Figure 3. Carbon Footprint of Each Packaging With 1kg Loading Capacity.

Based on the analysis as above, IBCs shows great advantages than other types of small volume packaging in terms of raw material nature and consumption, recycle rate and reuse times. Therefore, when safety requirement during hazardous chemical storage and transportation can be fulfilled, increasing the ratio of IBCs among hazardous chemical packaging could help reduce the overall carbon footprint in hazardous chemical packaging industry.

\subsection{Replacement Trend Formation and Carbon Footprint Prediction}

The result of carbon footprint analysis as shown in Figure 3 was obtained based on same load capacity $-1 \mathrm{~kg}$ hazardous chemical goods. From the result of the carbon footprint for $1 \mathrm{~kg}$ of hazardous chemicals, the following trends which represent the package carbon emission can be estimated easily to meet other situation. Table 4 shows the data of packaging amount collected from Tianjin Port in 2012-2015 and the prediction in the next five years (2016-2020). Number of each analyzed package was predicted by Grey Model, and Matlab was used in the calculation.

Table 4. Amount of Packaging From 2012 to 2015 and Prediction in 2016.

\begin{tabular}{ccccccccccc}
\hline \multirow{2}{*}{ Packing Type } & Capacity & $\mathbf{1 0}$ & \multicolumn{1}{c}{ Number } \\
\cline { 3 - 11 } & & $\mathbf{2 0 1 2}$ & $\mathbf{2 0 1 3}$ & $\mathbf{2 0 1 4}$ & $\mathbf{2 0 1 5}$ & $\mathbf{2 0 1 6}$ & $\mathbf{2 0 1 7}$ & $\mathbf{2 0 1 8}$ & $\mathbf{2 0 1 9}$ & $\mathbf{2 0 2 0}$ \\
\hline Fiberboard boxes & $25 \mathrm{~kg}$ & 419536 & 400346 & 492962 & 429665 & 469364 & 484318 & 499749 & 515672 & 532102 \\
\hline Fiberboard IBCs & $1000 \mathrm{~kg}$ & 876 & 924 & 1278 & 1510 & 1923 & 2425 & 3057 & 3856 & 4862 \\
\hline Plastic woven bags & $25 \mathrm{~kg}$ & 5671675 & 6925561 & 7018450 & 10879826 & 13366614 & 17280926 & 22341515 & 28884059 & 37342538 \\
\hline
\end{tabular}




\begin{tabular}{ccccccccccc}
\hline flexible IBCs & $1000 \mathrm{~kg}$ & 191016 & 225621 & 241779 & 288947 & 323309 & 367470 & 417663 & 474711 & 539551 \\
\hline Steel drums & $208 \mathrm{~kg}$ & 689345 & 708439 & 752724 & 880061 & 970593 & 1085423 & 1213839 & 1357440 & 1518048 \\
\hline Plastic drums & $210 \mathrm{~kg}$ & 116675 & 134810 & 137268 & 137872 & 139732 & 141302 & 142891 & 144497 & 146121 \\
\hline $\begin{array}{c}\text { Steel-plastic composite } \\
\text { IBCs }\end{array}$ & $1050 \mathrm{~kg}$ & 20876 & 23497 & 25084 & 24730 & 25678 & 26325 & 26988 & 27669 & 28366 \\
\hline
\end{tabular}

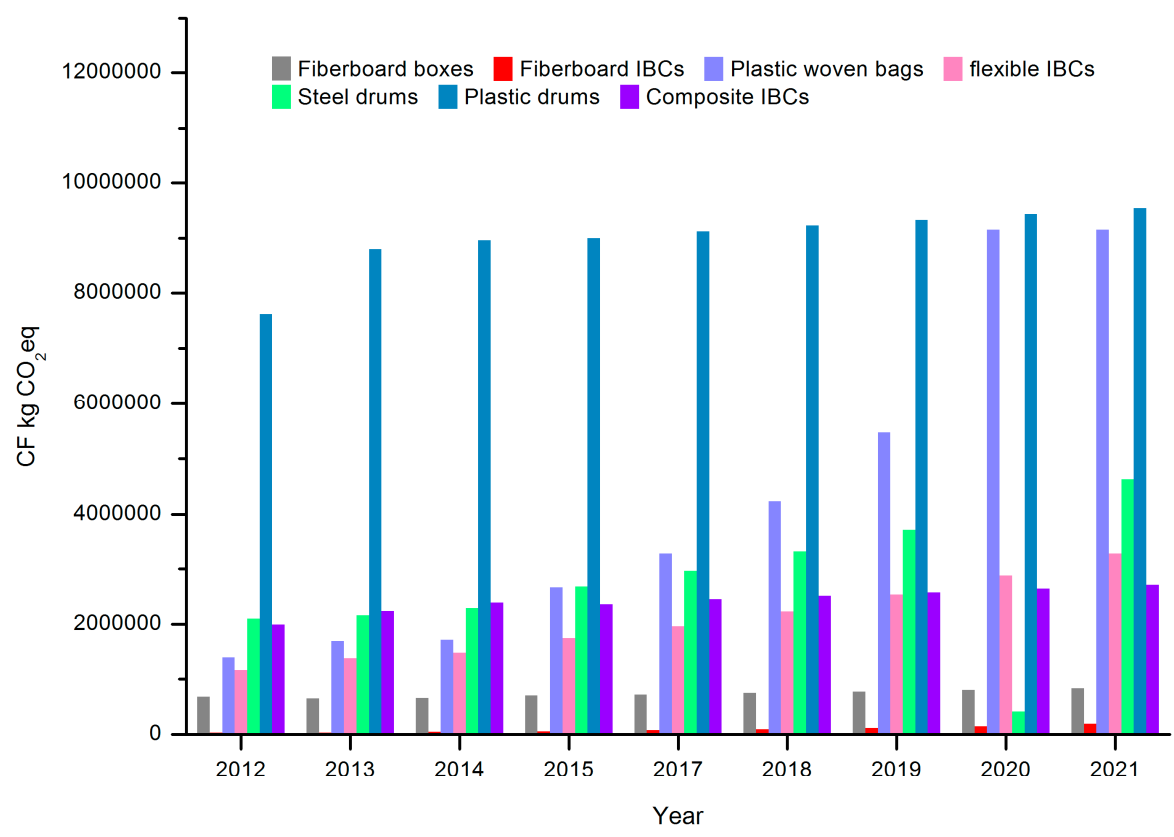

Figure 4. Growth Trend of Analyzed Packages From 2012 to 2020.

The prediction results show that the use of several kinds of packaging will grow fast in the next five years were plastic woven bag, fiberboard, flexible container bags and steel drums, while the use of plastic bucket will grow slowly. This basically meets the requirements of the sustainable development of the carbon footprint of hazardous chemical packaging. At the same time, it further confirms the impact of the carbon footprint by a number of factors, including material, consumption and recycling rate. The steel plastic composite IBCs showed no obvious advantage, and the main reason is that in the statistics analysis and calculation of the packaging, single use case is only considered. For multiple uses, statistics cannot be achieved at the same port, which caused the inaccuracy of carbon footprint calculation.

Since IBCs showed lower carbon footprint than other small volume packages, we can presume that if more IBCs could be used as hazardous chemical packaging, there would be less carbon footprint than general ones increasing the same amount. It is convinced that there is a significant drop in carbon emission when the numbers of IBC increased and the more it rises the more carbon emissions decline. Moreover, we made a carbon emission prediction on the basis of GM prediction. In the grey model results, different packages have various growth rates according to the historical data. Assuming that all packages would grow in the same rate (the average growth rate), the carbon footprint of 
2020 with the two kinds of growth rate was shown in Figure 5, where 2020' stands for the results of the average growth rate ones. Among the predicted different growth rates in 2020 compared to 2015, IBCs generally have higher growth rate than general packages (as shown in the 2020 line in Figure 5). When they share a same growth rate (2020' in Figure $5)$, which means IBCs grow slowly but general ones more quickly, and the total carbon footprint as shown in the Figure 5 can be more than the predicted one of varied growth rate. Hence, promoting the use of IBCs can lead the industry of hazardous chemicals' packaging to a low-carbon economy, achieving much more sustainable development.

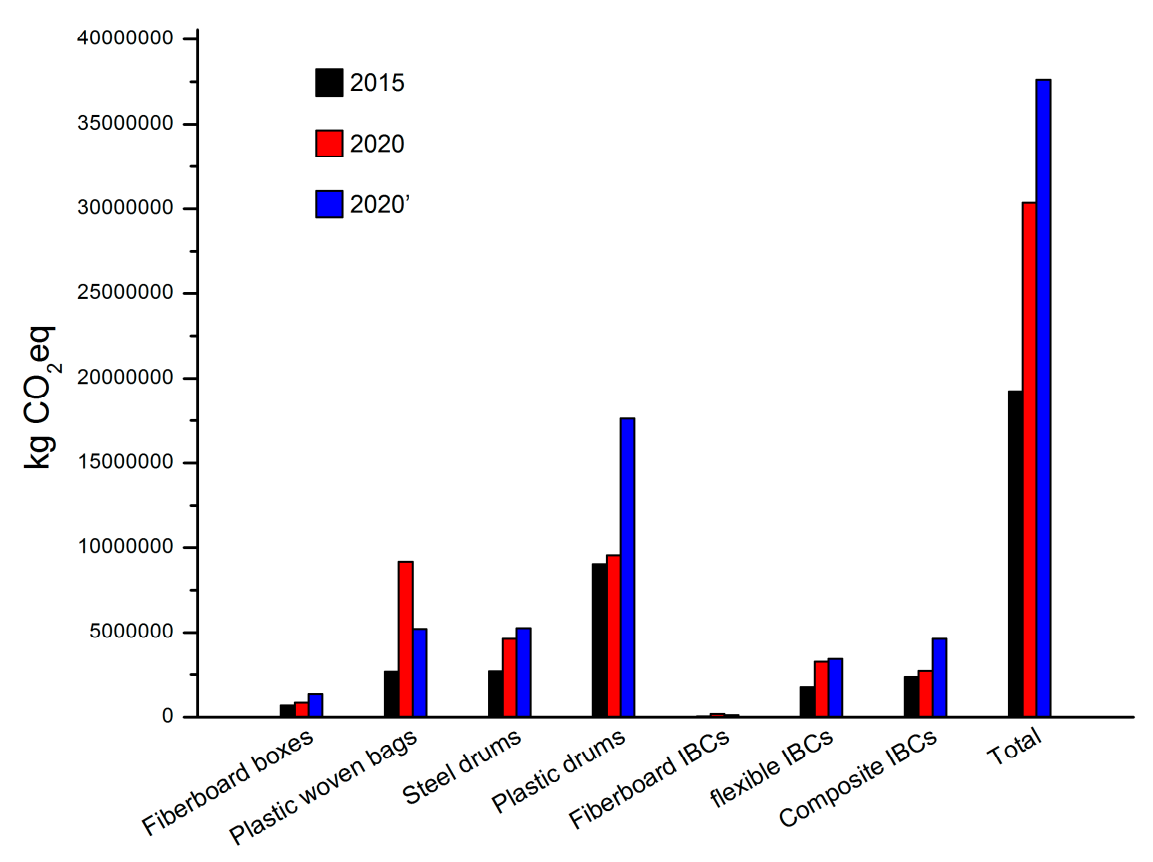

Figure 5. Carbon Emission Prediction (2020) With GM and Same Growth Rate Compared With 2015.

From Figure 6, it can be seen that simply comparing the annual carbon footprint in the absolute value is not very helpful to understand the trend of the packaging change, since export quantity of hazardous chemicals increased year by year and the use of packaging was also increased. Therefore, Grey model is used to predict the total export amount of hazardous chemicals in 2020, and the carbon footprint using the proportion of various packaging type as in 2015 and using the proportion of various packaging type in 2020 predicted by Gray model 2020', respectively. The results showed that with the packaging industry adjustment, great impact on the overall change of carbon footprint can be achieved - reducing the absolute carbon footprint of $13904751.95 \mathrm{~kg} \mathrm{CO}_{2}$ eq., and the relative impact of $45.80 \%$. 


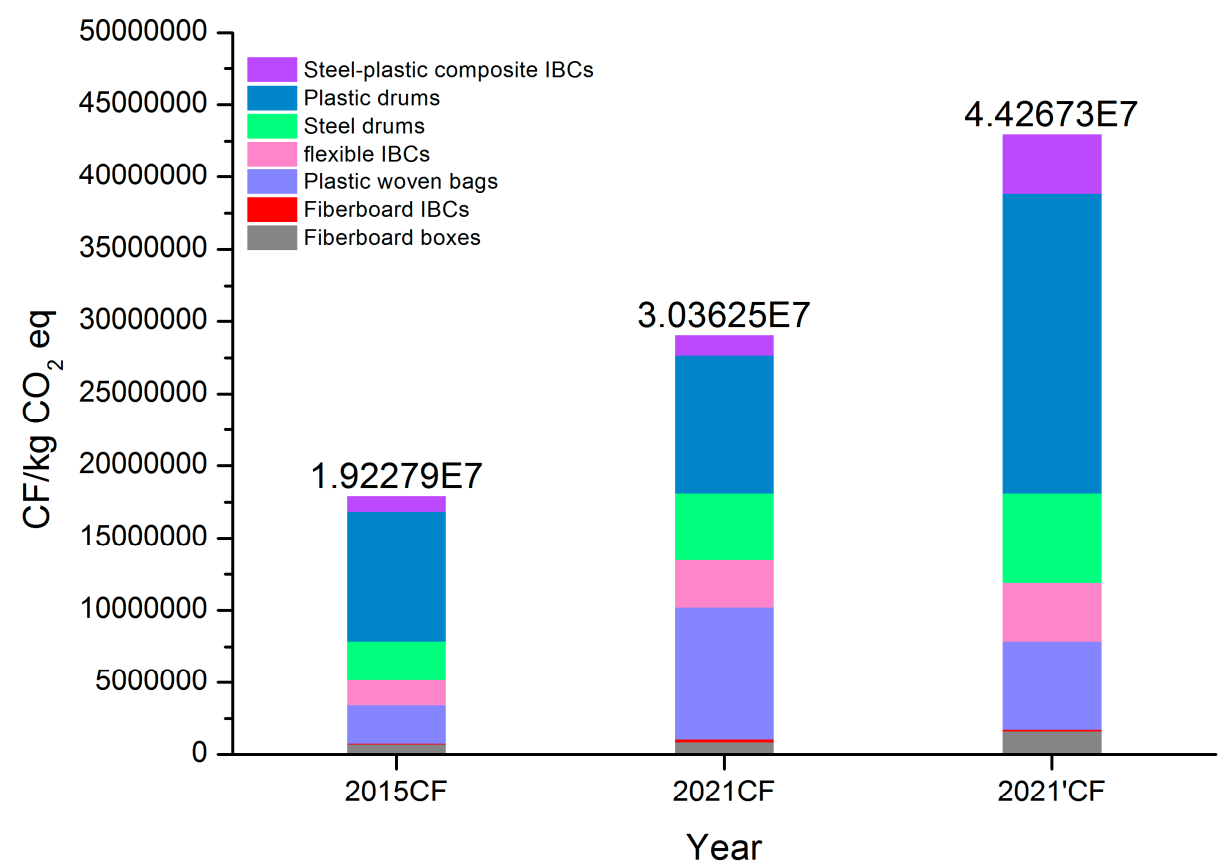

Figure 6. Carbon Emission Prediction (2020) With GM and Same Growth Rate 2015.

\section{Conclusion}

This study evaluated the carbon footprints of seven hazardous chemical packaging, with the conception of life cycle- from 'cradle-to-grave'. The findings presented in this paper revealed useful information for replacing trends in hazardous chemical packaging. In overall, packaging made of different materials and with different volumes will have different carbon footprint. In the premise of not affecting the safety of hazardous chemical storage and transportation, and not influencing their use, reasonably increasing packaging capacity, reducing packaging material, increasing the reuse of packaging and recycle rate of packaging material will help reduce overall carbon emissions of hazardous chemicals packaging.

IBCs appeared to be a better choice of lower carbon footprint than the other small volume packages made of similar material. Moreover, prediction on batches packaging usage and carbon emissions at Tianjin Port in 2016-2020 showed both of these two numbers increased. However, if the use of IBCs increases, carbon emissions in 2016-2020 decrease significantly. It can be concluded that IBCs can be a much more environmental-friendly choice in reducing the carbon emissions. In order to achieve the goal of low carbon economy, promoting the use of IBCs is a crucial change which must be made in the future.

This study still has limitations due to the focus on Tianjin Port, although it could well represent the status of hazardous chemical packaging use in North China. Further assessment should be carried out to cover more regions.

Acknowledgements: The authors thank the financial support from General Administration of Quality 
Supervision, Inspection and Quarantine of the People's Republic of China (No. 2012IK212 \& 2016IK254) .The author appreciated the support from related enterprises in Tianjin area on data collection and analysis in this study.

Author Contributions: All authors contributed equally to this work.

Conflicts of Interest: The authors declare no conflict of interest.

\section{References}

1. Griffin, R.C.J.; Sacharow, S.;Brody, A.L. Principles of Package Development. 2ed ed. Berlin: Springer Netherlands; 1985.

2. Lee, E.; Qi, H.;Gea, H.C. Decision Making Framework Using Probabilistic Pareto for Sustainable Packaging Life Cycle Assessment. Journal of Applied Packaging 2016, 8, 17-31.

3. Fu, Y.B.; Xu, W.C.; Jiang, Y.R.;Zhou, G. A Case Study of Carbon Footprint on Liquor Packaging. Applied Mechanics and Materials 2013, 262, 577-580.

4. Jiang, P.; Chen, Y.H.; Xu, B.; Dong, W.B.;Kennedy, E. Building Low Carbon Communities in China: The Role of Individual's Behaviour Change and Engagement. Energy Policy 2013, 60, 611-620.

5. Keoleian, G.A.; Phipps, A.W.; Dritz, T.;Brachfeld, D. Life Cycle Environmental Performance and Improvement of a Yogurt Product Delivery System. Packaging Technology and Science 2004, 17, 85-103.

6. Cleary, J. Life Cycle Assessments of Wine and Spirit Packaging at the Product and the Municipal Scale: A Toronto, Canada Case Study. Journal of Cleaner Production 2013, 44, 143-151.

7. Albrecht, S.; Brandstetter, P.; Beck, T.; Fullana-i-Palmer, P.; Grönman, K.; Baitz, M.; Deimling, S.; Sandilands, J.;Fischer, M. An Extended Life Cycle Analysis of Packaging Systems for Fruit and Vegetable Transport in Europe. International Journal of Life Cycle Assessment 2013, 18, 1549-1567.

8. Feng, Z.J.; Hou, Q.; Mao, G.Z.;Zhao, L. Comparison Study of Life Cycle Assessment for Dangerous Goods Packaging and Intermediate Bulk Container. Packaging Engineering 2013, 34, 48-53.

9. Accorsi, R.; Cascini, A.; Cholette, S.; Manzini, R.;Mora, C. Economic and Environmental Assessment of Reusable Plastic Containers: A Food Catering Supply Chain Case Study. International Journal of Production Economics 2014, 152, 88-101.

10. Pasqualino, J.; Meneses, M.;Castells, F. The Carbon Footprint and Energy Consumption of Beverage Packaging Selection and Disposal. Journal of Food Engineering 2011, 103, 357-365.

11. Poovarodom, N.; Ponnak, C.;Manatphrom, N. Comparative Carbon Footprint of Packaging Systems for Tuna Products. Packaging Technology and Science 2012, 25, 249-257.

12. Saleh, Y. Comparative Life Cycle Assessment of Beverages Packages in Palestine. Journal of Cleaner Production 2016, 131, 28-42.

13. Wikström, F.; Williams, H.; Verghese, K.;Clune, S. The Influence of Packaging Attributes on Consumer Behaviour in Food-Packaging Life Cycle Assessment Studies - a Neglected Topic. Journal of Cleaner Production 2014, 73, 100-108.

14. TDG. Tdg 2015. Geneva: United Nations publication; 2015. p. 265.

15. Jacobs, M.M.; Malloy, T.F.; Tickner, J.A.;Edwards, S. Alternatives Assessment 
Frameworks: Research Needs for the Informed Substitution of Hazardous Chemicals. Environmental Health Perspectives 2016, 124, 265-280.

16. Tang, Z.W.; Huang, Q.F.;Yang, Y.F. China: Overhaul Rules for Hazardous Chemicals. Nature. [Correspondence]. 2015, 525, 455-455.

17. Bethke, J.; Goedecke, T.jJahnke, W. Permeation through Plastic Dangerous Goods Packaging During Transport in Freight Containers - Detection of Potentially Explosive Mixtures in Containers under Normal Conditions of Carriage. Packaging Technology and Science 2013, 26, 1-15.

18. Schlick-Hasper, E.; Seidler, O.; Goedecke, T.;Kraume, M. Measurement of Helium Leakage Rates through Closures of Dangerous Goods Packagings for the Assessment of Potentially Explosive Mixtures in Freight Containers. Packaging Technology and Science 2015, 28, 959-985.

19. Weltschev, M. Comparison between Material Parameters of Polyethylene Grades and the Test Performance Behaviour of Packaging for the Transport of Dangerous Goods. Packaging Technology and Science 2011, 24, 361-371.

20. Wang, C.J.;Ducruet, C. Regional Resilience and Spatial Cycles: Long-Term Evolution of the Chinese Port System (221bc-2010ad). Tijdschrift voor economische en sociale geografie 2013, 104, 521-538.

21. Rebitzer, G.; Ekvall, T.; Frischknecht, R.; Hunkeler, D.; Norris, G.; Rydberg, T.; Schmidt, W.P.; Suh, S.; Weidema, B.P.;Pennington, D.W. Life Cycle Assessment: Part 1: Framework, Goal and Scope Definition, Inventory Analysis, and Applications. Environment International 2004, 30, 701-720.

22. Mcdonough, W.; Braungart, M.;Bollinger, A. Cradle-to-Cradle Design: Creating Healthy Emissions - a Strategy for Eco-Effective Product and System Design. Journal of Cleaner Production 2007, 15, 1337-1348.

23. BS EN ISO 14040 Environmental Management-Life Cycle Assessment-Principles and Framework. Geneva: International Organization for Standardization; 2006.

24. Rugani, B.; Vázquez-Rowe, I.; Benedetto, G.;Benetto, E. A Comprehensive Review of Carbon Footprint Analysis as an Extended Environmental Indicator in the Wine Sector. Journal of Cleaner Production 2013, 54, 61-77.

25. IPCC. Climate Change 2007: Synthesis Report. An Assessment of the Intergovernmental Panel on Climate Change. Intergovernmental Panel on Climate Change 2007.

26. Cederberg, C.; Henriksson, M.;Berglund, M. An Lca Researcher's Wish List - Data and Emission Models Needed to Improve Lca Studies of Animal Production. Animal 2013, 7, 212-219.

27. Herva, M.; Franco, A.; Carrasco, E.F.;Roca, E. Review of Corporate Environmental Indicators. Journal of Cleaner Production 2011, 19, 1687-1699.

28. Ramachandra, T.V.;Shwetmala. Decentralised Carbon Footprint Analysis for Opting Climate Change Mitigation Strategies in India. Renewable and Sustainable Energy Reviews 2012, 16, 5820-5833.

29. Liu, S.F.;Forrest, J.Y.-L. Grey Information: Theory and Practical Applications. Berlin: Springer ed2006.

30. Liu, S.F.; Forrest, J.Y.-L.;Yang, Y. Advances in Grey Systems Research. Journal of Grey System 2013, 25, 1-18. 
31. Wu, L.F.; Liu, S.F.; Liu, D.L.; Fang, Z.G.;Xu, H.Y. Modelling and Forecasting Co2 Emissions in the Brics (Brazil, Russia, India, China, and South Africa) Countries Using a Novel Multi-Variable Grey Model. Energy 2015, 79, 489-495.

32. Zhou, P.; Ang, B.W.;Poh, K.L. A Trigonometric Grey Prediction Approach to Forecasting Electricity Demand. Energy 2006, 31, 2839-2847.

33. Hamzacebi, C.;Es, H.A. Forecasting the Annual Electricity Consumption of Turkey Using an Optimized Grey Model. Energy 2014, 70, 165-171.

34. BS EN ISO 15750-2 Packaging - Steel Drums - Part 2 : Non-Removable Head (Tight Head) Drums with a Minimum Total Capacity of 212 L, 216,5 L and 230 L. Geneva, Switzerland: International Organization for Standardization; 2008.

35. BS EN ISO 20848-2 Packaging - Plastics Drums - Part 2: Non-Removable Head (Tight Head) Drums with a Nominal Capacity of 208,2 L and 220 L. Geneva, Switzerland: International Organization for Standardization; 2006.

36. Hellweg, S.;Milà i Canals, L. Emerging Approaches, Challenges and Opportunities in Life Cycle Assessment. Science 2014, 344, 1109-1113. 